\title{
PROCESSO DE INTERNACIONALIZAÇÃO E O IMPACTO NAS FINANÇAS DA
} EMPRESA: O CASO LUSAMAR

\author{
L. de F. L. G. da Costa ${ }^{1}$, R. N. C. Parente ${ }^{1}$, G. L. P. Camelo ${ }^{1}$ \\ ${ }^{1}$ Instituto Federal de Educação, Ciência e Tecnologia do Rio Grande Norte \\ lucialucio@gmail.com,rnonato@cefetrn.br, gerda@cefetrn.br \\ Artigo submetido em dezembro/2009 e aceito em março/2011
}

\begin{abstract}
RESUMO
O desenvolvimento de competências empresariais são as bases necessárias ao planejamento estratégico de uma organização. Segundo Porter (1989) a eficiência operacional não é condição suficiente para o bom desempenho estratégico, mas é necessária. Nesse sentido o presente artigo vida apresentar uma análise sobre o impacto financeiro de uma empresa a partir do processo de internacionalização. Para tanto foi realizado um estudo de caso com empresa do segmento de pescado sob a perspectiva da ampliação da sua capacidade produtivo focalizando o critério de margem de contribuição para avaliação da viabilidade do processo de internacionalização da empresa e os respectivos impactos nas finanças da empresa. Constatou-se que a referida empresa, por meio do plano de internacionalização pode adentrar no mercado internacional. Essa ferramenta de estudo da realidade financeira da empresa, permite a compreensão do contexto organizacional projetado de forma que se analisem os impactos causados por essa mudança. Nessas condições, a empresa pode observar o grau de viabilidade da ação na busca de identificar o acesso reduzindo significativamente as possibilidades de fracasso.
\end{abstract}

PALAVRAS-CHAVE: Processo de internacionalização, Planejamento estratégico; Finanças

\section{INTERNATIONALIZATION PROCESS AND THE IMPACT IN THE FINANCES OF THE COMPANY: LUSAMAR'S CASE}

\begin{abstract}
The development of enterprise abilities is the necessary bases to the strategic planning of an organization. As Porter (1989) the operational efficiency is not enough condition for the good strategic performance, but it is necessary. In this direction the present article life to present an analysis on the financial impact of a company from the internationalization process. For in such a way a study of only case with company of the segment of fished was carried through under the perspective of the magnifying of its productive capacity focusing the criterion of edge of contribution for evaluation of the viability of the process of internationalization of the company and the respective impacts in the finances of the company. One evidenced that the cited company, by means of the internationalization plan can intent in the international market. This tool of study of the financial reality of the company, allows the understanding of the projected context organizational of form that if analyzes the impacts caused for this change. In these conditions, the company can observe the degree of viability of the action in the search to identify to the access reducing significantly the possibilities of failure
\end{abstract}

KEY-WORDS: Internationalization process; Strategic planning; Finances 


\section{PROCESSO DE INTERNACIONALIZAÇÃO E O IMPACTO NAS FINANÇAS DA EMPRESA: O CASO LUSAMAR}

\section{INTRODUÇÃO}

O processo de globalização dos negócios, aliado ao avanço tecnológico dos meios de produção e comunicação, está acelerando o ritmo de mudanças no ambiente organizacional. Após a concepção universalista e hegemônica de fábricas tayloristas-fordista, voltadas para produção em larga escala, observa-se o surgimento de sistemas complexos que buscam integrar informações e processos na tentativa de gerar vantagem competitiva (KIM, 2007). Essa reestruturação se deve ao processo de internacionalização das economias que levaram as empresas a integrar em escala global sua produção e distribuição.

Após os anos 90 com a abertura do mercado brasileiro surgiu a necessidade de se estabelecer saldos positivos na balança comercial. Isso se intensificou com uma série de incentivos promovidos pelo governo para que as empresas brasileiras tivessem competitividade frente ao mercado internacional. $\mathrm{O}$ fato é que a iniciativa, aliada à falta de planejamento estratégico das organizações, levou as empresas a sofrer sérios prejuízos. O que para o governo era visto como oportunidade, para as empresas, que até então estavam despreparadas, era fonte de ameaças comerciais.

De acordo com Rocha e Melo (2002), depois de muitas décadas de políticas de substituição das importações, as empresas nacionais estavam despreparadas para competir com o mercado internacional. Mas, foi diante do cenário adverso e com ausência de um planejamento eficiente, que essas organizações passaram a competir internacionalmente.

Nesse sentido, as organizações precisavam desenvolver em tempo hábil estratégias que pudessem promover competitividade. Com o advento da globalização e a aceleração da dinâmica dos mercados, as empresas tiveram que se adaptar a uma realidade frenética, a fim de garantir sua manutenção no mercado. As motivações básicas para a criação de novas estratégias são tradicionalmente traduzidas pela necessidade de apropriação de novos riscos, desenvolvimentos de novas tecnologias e barganha de mercado.

O planejamento estratégico como ferramenta essencial de uma organização passou a integrar as várias áreas da empresa, orientando na direção de suas metas. Assim as empresas brasileiras vislumbravam um novo paradigma produtivo aliado a estratégias de competição em escala global.

Em decorrência dessas mudanças de cenário, e, por conseguinte, na arena operacional, a área financeira, como um dos pilares em um planejamento estratégico, tem papel fundamental na condução do processo de internacionalização, visto que é a partir das ferramentas de analise financeira que se têm condições mais tangíveis de observar sua viabilidade.

Segundo Asaf Neto e Silva (1997) o planejamento estratégico, auxiliado pelo planejamento financeiro e, por conseguinte, de fluxo de caixa, a presente investigação dispõe sobre o plano de internacionalização, observando questões que partem da macroeconomia e de pesquisa de mercado a orçamento financeiros de curto prazo para que se possa vislumbrar a possibilidade de inserção no mercado internacional.

Para tanto, utilizou-se como objeto de estudo, uma empresa de pescado, atuante no mercado do Rio Grande do Norte, cuja avaliação das condições de alavancagem operacional de 
crescimento no mercado determinará a viabilidade da iniciativa de inserção de seu produto no mercado externo. Nesse sentido o presente artigo visa apresentar como o processo de internacionalização gera impactos nas finanças da em estudo concerne na simulação de modificação do fluxo de caixa operacional da empresa sendo como principal indicador, a margem de contribuição operacional. Dito de outo modo, a margem de contribuição da empresa foi utilizada como critério de análise em relação aos impactos financeiros gerados em seu processo de internacionalização. Assim a pesquisa se caracteriza como descritivoexploratória de caráter qualitativo, já que irá avaliar um fenômeno organizacional a partir de um estudo de caso através da metodologia de análise de conteúdo (VERGARA, 1997; BARDIN, 2004).

\section{PLANEJAMENTO ESTRATÉGICO E TÁTICO COM FOCO EM FINANÇAS}

De acordo com Oliveira (1991) o planejamento significa à formulação sistemática de objetivos e ações alternativas que direcionam a melhor a escolha sobre a ação. Também diz respeito a implicações futuras de decisões presentes, pois é um processo de decisões interrelacionadas e interdependentes que visam alcançar objetivos previamente estabelecidos.

$\mathrm{Na}$ tentativa de inserção no mercado internacional verifica-se que essa necessidade é primordial para obter bons resultados nesse mercado, empiricamente, é uma ação economicamente arriscada, por essa razão é que alguns autores propõem o plano de internacionalização que consiste na organização de ações estratégicas que obedecem a uma ordem cronológica visando à inclusão no comércio internacional.

O planejamento estratégico organizacional, que engloba o planejamento estratégico e a administração estratégica, deve ser visto como um instrumento de mudanças numa organização. Considera-se como planejamento estratégico o processo que consiste na análise sistemática dos pontos fortes e pontos fracos, e das oportunidades e ameaças do meio ambiente - de forma a estabelecer objetivos, procedimentos e ações que possibilitem um aumento da competitividade.

Gitman (2005) entende que o planejamento financeiro é um importante aspecto das atividades da empresa porque orienta a direção a coordenação e o controle das providencias tomadas pela organização com o intuito de atingir seus objetivos. Assim o planejamento financeiro atende a basicamente dois processos: planejamento de caixa e planejamento de resultado. $\mathrm{O}$ primeiro abrange elaboração de orçamento de caixa, ou seja, envolve questões relacionadas ao curto prazo. O segundo por sua vez exige elaboração de demonstrações projetadas.

O processo de planejamento financeiro inicia com elaboração de planos financeiros de longo prazo ou estratégicos. Dessa forma, eles orientam a formulação de planos e orçamentos de curto prazo (operacionais). Em linhas gerais o planejamento estratégico de longo prazo direciona as ações do planejamento operacional.

\section{PROCESSO DE INTERNACIONALIZAÇÃO}

De acordo com Anderson e Gatignon (1996) e Barney (1996) os estudos sobre estratégia apontam para um direcionamento cujas bases residem em: plano, padrão, posição, manobra e perspectiva. Esses pilares dizem respeitos às ações que devem ser tomadas pelas organizações a fim de garantir condições competitivas no mercado. 
Para Privedelli (1997) a estratégia de internacionalização vista sob a perspectiva de plano de ação engloba fatores que devem ser observados para desenvolvimentos de uma estrutura no marcado doméstico com vista ao mercado internacional.

O planejamento é uma das etapas das funções administrativas reconhecida desde a teoria clássica a autores mais modernos, como a etapa que demanda o maior conjunto de variáveis voltada a previsão das subseqüentes. Em linhas gerais, para que as demais funções ocorram de forma satisfatória é importante que o planejamento tenha sido bem elaborado. O autor explica (1997) que é possível definir isoladamente a função planejamento como sendo o processo sistemático e contínuo de preparação do futuro da empresa. O processo de internacionalização deve observar uma série de variáveis que distingue o planejamento para o mercado interno, nesse sentido Cain (1970 apud Previdelli, 1998) elaborou um esquema, cujas variáveis estão dispostas para adequação da empresa a realidade do mercado externo conforme figura a seguir:

\section{Quadro1: O Planejamento doméstico em contraposição ao planejamento internacional}

\section{DOMÉSTICO}

1. Língua e nacionalidade únicas

2. Mercado relativamente homogêneo

3. Dados disponíveis são normalmente precisos e fáceis de serem obtidos

4. Fatores políticos são relativamente pouco importantes

5. Relativa liberdade de interferência governamental

6. A empresa isolada exerce efeito insignificante sobre o ambiente

7. A atitude chauvinista ajuda

8. Ambiente empresarial relativamente estável

9. Cenário econômico/financeiro muitas vezes estável

10. Moeda única

11. As "regras do jogo empresarial" estão consolidadas e são bem conhecidas 12. A administração geralmente está habituada a compartilhar de responsabilidades e a usar controles financeiros

\section{INTERNACIONAL}

1. Fatores multilíngues, multinacionais e multiculturais

2. Mercados fragmentados e diversificados

3. Coleta de dados é tarefa formidável, exigindo orçamentos e volume de pessoal muito maiores

4. Fatores políticos freqüentemente são de importância vital

5. Envolvimento em planos econômicos nacionais; o governo influencia as decisões das empresas

6. Distorções "gravitacionais" criadas por grandes empresas

7. A atitude chauvinista atrapalha

8. Ambientes múltiplos, muitos dos quais são altamente instáveis (mas podem ser muito lucrativos)

9. Variedade de cenários econômicos e financeiros, desde os excessivamente conservadores até os extremamente inflacionários

10. Moedas com graus de estabilidade e valores reais diferentes

11. Regras distintas, modificáveis e incertas

12. A administração freqüentemente é autônoma e não está familiarizada com orçamentos e controles

Fonte: CAIN, William W. Internacional Planning: Mission Impossible. Combria Juunal of Wold Business, Jully-August, 1970, p58 apud PREVIDELLIi (1998).

A relevância da estratégia como padrão configuram aspectos relativos ao processo produtivos que devem estar adequados a demanda internacional. Essa matéria também pode ser lida sob como o desenvolvimento de melhoramento continuo dos processos a fim de garantir um padrão que caracterize a empresa.

A estratégia como posição, por sua vez refere-se às condições a localização de determinados produtos nos mercados, ou seja, o conceito de posição é estabelecido de acordo com as 
definições e objetivos estratégicos pretendidos pela organização com a comercialização de determinado bem, observando a relação deste com o ambiente.

A estratégia como manobra condiz com a necessidade da organização desenvolver um caminho diferenciado da concorrência para atingir seu objetivo sem que os concorrentes possam lhe alcance e ou copiar em tempo hábil.

A estratégia de perspectiva é baseada na análise feita pela organização para sua estrutura interna e para o mercado doméstico vislumbrando o desenvolvimento de ações e metas voltadas para o mercado externo.A internacionalização tem sido considerada um caminho natural das organizações tendo em vista o conjunto de variáveis econômicas que levaram as economias a funcionar de forma globalizada. A mundialização de capitais e os avanços tecnológicos, sobretudo, no que refere a telecomunicações, produzem um cenário de negociações dinâmicas a nível mundial.

Em pesquisa sobre transformação e revitalização analisaram algumas empresas globais e destacaram cinco estratégias importantes para manutenção das empresas no mercado internacional:

1. Eliminação de níveis hierárquicos para adquirir sensibilidade;

2. Aproveitamento das capacidades globais: criação de capacidades específicas para obtenção de vantagens competitivas reais no escopo e escala globais;

3. Criação de novos papéis para o administrador, necessidade de maior sinergia e capacitação em aspectos internacionais.

4. Reinvenção das estratégias de liderança da indústria

5. Novas ferramentas para gestão de mudanças globais:

a) escolha dos objetivos a serem alcançados; b) criação de novos padrões de mudanças: avaliação de novas capacidades e vetores de inovação e de transferência de conhecimento; c)doação de novos estilos de escala global: definição, implementação das estratégias e aplicação de processos gerenciais.

Na busca de importadores, pode-se recorrer a instituições que trabalham na promoção do comércio exterior, como embaixadas, câmaras de comércio bilaterais, bancos, empresas de consultoria, empresas de promoção comercial dentre outras, a própria Internet é uma grande ferramenta de busca de informações comerciais.

Dessa maneira pode-se entender a operação de exportação, assim como a estratégia empresarial que seguindo o conceito do iceberg (visão minimizada do evento que abrange competências maiores) consiste em uma serie de fatores intervenientes na gestão que não são identificados a primeira vista (MINERVINI, 2001). 


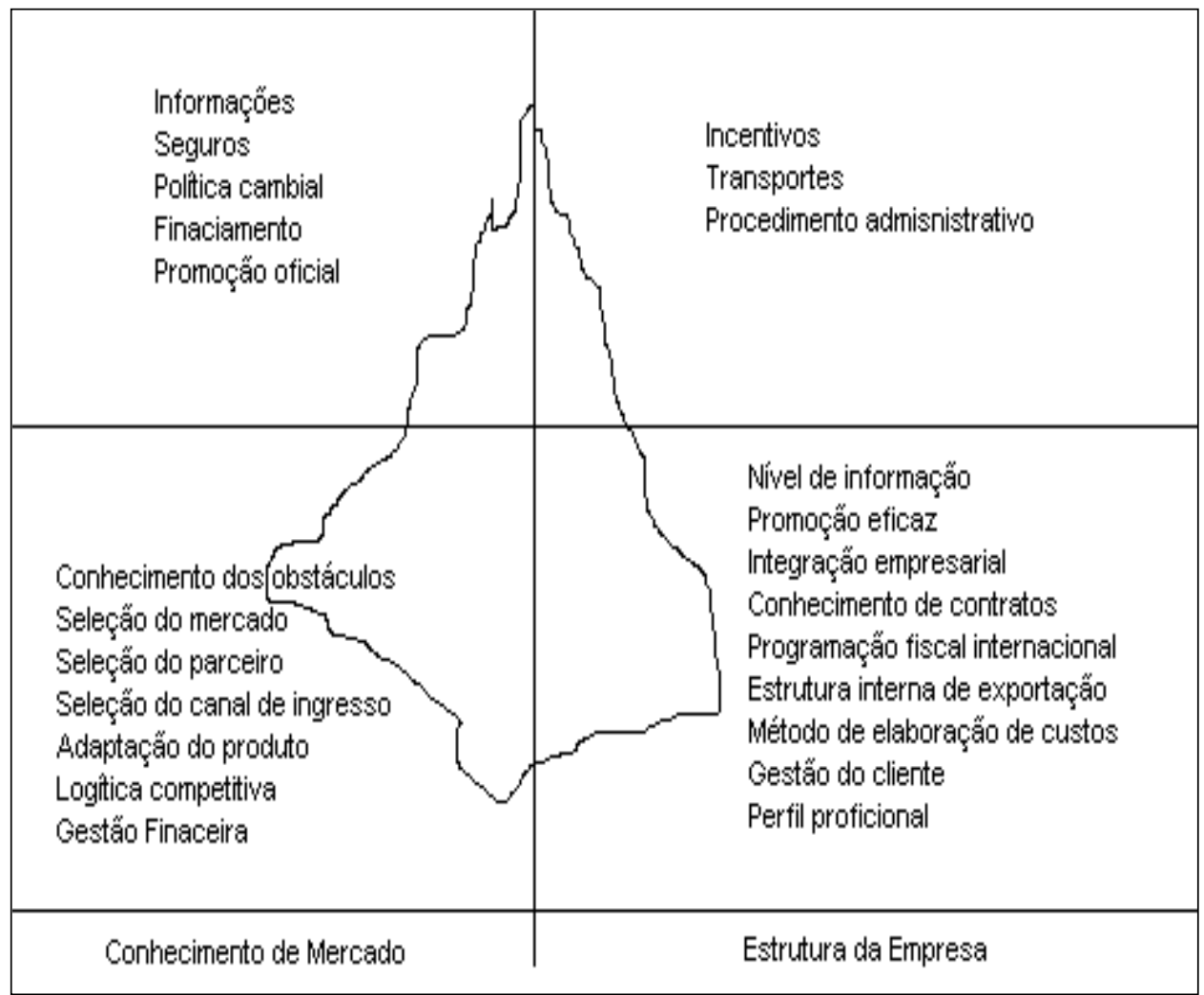

Figura 1: Perspectiva do ICEBERG no processo de exportação Fonte: Adaptado, Minervini, 2001

Ao realizar essa avaliação a empresa tem condições de elaborar as diretrizes do plano de internacionalização que consiste no estudo da atual situação da empresa para que se possa realizar a hipótese da base de plano. Para tanto, deve-se ter informações do contexto interno da empresa e dos dados macro-conjunturias.

\section{DESENVOLVIMENTOS DE COMPETENCIAS FINACEIRAS ATRAVÉS DA ESTRATÉGIA DE INTERNACIONALIZAÇÃO}

A Lusamar Pescados Pesca e Comércio é uma micro-empresa de pescados de água salgadas, que atua no mercado interno fornecendo pescado fresco caracterizado como tipo exportação para empresas exportadoras e comercializa também diretamente com consumidores como restaurantes e hotéis que compram o restante da produção de peixes comumente consumidos no mercado na realidade norte-rio-grandense. Como amostra a empresa forneceu um grupo de dados que consiste nos relatórios de fluxo de caixa no período de um exercício contábil.

A partir do estudo desse fluxo de caixa serão observados pontos relevantes à produtividade e, por conseguinte, ao setor financeiro da empresa. De acordo com a empresa objeto de estudo o pescado vendido no mercado interno atualmente é cerca de $40 \%$ mais barato que o destinado à exportação. Tendo em vista o preço médio do pescado exportado (de fevereiro de 2005 a fevereiro de 2006) US\$ FOB 4,08, podemos simular que no mercado interno o produto é vendido a US\$ FOB 2,86. A formação do preço do produto compromete-se 35,41\% de sua receita em custos variáveis, conforme observado na tabela que segue: 
COSTA, PARENTE \& CAMELO (2011)

Tabela 1: Fluxo de Caixa Médio da Lusamar Pescados

FLUXO DE CAIXA MÉDIO

\begin{tabular}{|crr|}
\hline RECEITA DE VENDAS & $\mathbf{R} \$$ & $\mathbf{1 4 . 1 8 2 , 0 4}$ \\
\hline CUSTO DE PRODUOS VENDIDOS & $\mathrm{R} \$$ & $4.143,39$ \\
\hline LUCRO BRUTO & $\mathbf{R} \$$ & $\mathbf{1 0 . 0 3 8 , 6 5}$ \\
\hline DESPESAS COM VENDAS & $\mathrm{R} \$$ & 878,62 \\
\hline DESPESAS ADMINISTRATIVA & $\mathrm{R} \$$ & $1.829,26$ \\
\hline DEPRECIAÇÃO & $\mathrm{R} \$$ & - \\
\hline LUCRO OPERACIONAL & $\mathbf{R} \$$ & $\mathbf{7 . 3 3 0 , 7 7}$ \\
\hline DESPESAS FINANCEIRAS & $\mathrm{R} \$$ & - \\
\hline LUCRO ANTES DO IR & $\mathrm{R} \$$ & $7.330,77$ \\
\hline PROVISÄO PARA IR & $\mathrm{R} \$$ & $2.199,23$ \\
\hline LUCRO LIQUIDO & $\mathbf{R} \$$ & $\mathbf{5 . 1 3 1 , 5 4}$ \\
\hline
\end{tabular}

Fonte: Lusamar (2006)

É importante ressaltar que os dados fornecidos no fluxo de caixa médio não permitem saber a distinção exata dos custos, por essa razão, é importante observar que os valores são aproximados.

A Lusamar afirma que atualmente tem operado utilizando cerca de $80 \%$ de sua capacidade produtiva. Dessa forma, pode-se afirmar que para um crescimento produtivo de $20 \%$ a empresa não terá que onerar a produção com novos investimentos, até porque o padrão de qualidade e higiene existente na empresa é o mesmo exigido pelos exportadores. De acordo com os parâmetros de equilíbrio propostos por Minervini (2001), para que a empresa possa apresentar estabilidade nos canais de distribuição nos mercado interno e externo, é prudente manter a relação de $40 \%$ e $60 \%$ ou de $30 \%$ e $70 \%$ para cada um desses mercados.

Observando esses parâmetros e os relacionando com a capacidade produtiva da empresa objeto de estudo, sugere-se a opção de destinar cerca de $20 \%$ da produção ao mercado externo e manter $80 \%$ para o mercado interno.

Dessa forma a empresa poderá continuar a atender o mercado interno com o mesmo volume de negócio e terá que projetar um crescimento de $20 \%$ da produção, o que não oportunizará a geração de despesas adicionais já que a sua capacidade produtiva apresenta a ociosidade de 20\%. Apesar de ser um percentual modesto, ainda assim, é considerado positivo, pois diminui os riscos da iniciativa de distribuição no mercado internacional.

Para esse incremento devem ser observados os fatores que contribuíram para o aumento do custo variável tais como embalagem e despesas portuárias, por essa razão, foi realizada a formação de preço do produto para o mercado internacional, para confrontar com o preço praticado no mercado com vistas a analisar a absorção do custo extra e a margem de contribuição para observando o reflexo no lucro da empresa, conforme tabela que segue: 
Tabela 2: Formação do preço do pescado para o mercado externo

\begin{tabular}{|l|r|}
\hline Preço & $\mathbf{2 , 8 6}$ \\
\hline ICMS (-) & 0,42 \\
\hline PIS (-) & 0,02 \\
\hline CONFINS (-) & 0,09 \\
\hline SubTOTAL & $\mathbf{2 , 3 3}$ \\
\hline Lucro Mercado Interno (-) & 0,29 \\
\hline Embalagem exportação (+) & 0,29 \\
\hline SubTOTAL & $\mathbf{2 , 3 3}$ \\
\hline Margem de lucro externo (+) & 0,57 \\
\hline Transporte e seguro (+) & 0,29 \\
\hline Despachante aduaneiro (+) & 0,03 \\
\hline Despesas portuária (+) & 0,06 \\
\hline Preço FOB s/ com.agente & $\mathbf{3 , 2 8}$ \\
\hline
\end{tabular}

Fonte: Lusamar (2006)

Depois de observado que o produto no mercado nacional era $70 \%$ do valor do produto destinado ao mercado internacional, chegou-se a cifra média de U\$D 2,86. A partir de então foi possível realizar a formação do preço do produto considerando despesas tributárias, operacionais e de embalagem.

De acordo com a lei Kandir (Lei complementar $n^{\circ}$ 87, de 13 de setembro de 1996) os bens destinados à exportação estão isentos de alguns tributos e contribuições. No caso de pescado fresco o imposto sobre produto industrializado não é cobrado. Por essa razão houve apenas a dedução do PIS (Programa de Integração Social) que é 0,65\% sobre o preço do bem; o Cofins (Contribuição para o Financiamento da Seguridade Social) equivalente a 3\% da mercadoria e o ICMS (Imposto sobre Circulação de Mercadoria) que é de $17 \%$.

No mercado não há custo de embalagem, no entanto, é sabido por ela, que a embalagem para o produto ser comercializado no mercado externo agrega cerca de $10 \%$ em seu preço.

Em se tratando das despesas portuárias, de despacho aduaneiro e de transporte interno são adicionadas respectivamente $1 \%, 2 \%$ e $10 \%$ do preço do produto.

Conforme comentado com a empresa, condicionou-se uma margem de lucro interno de $10 \%$ exclusivamente para a comercialização de pescado, já para o produto exportado, foi estipulado cerca de $20 \%$ de lucratividade.

Dentro desses parâmetros, e considerando a comercialização do produto como FOB (Free on Bord, o preço do pescado pode ser ainda mais competitivo (U\$D 3,28) que o valor médio que é praticado atualmente no mercado (U\$D 4,08)). Isso propicia a empresa maior mobilidade na comercialização dos bens, podendo barganhar clientes em virtude de ter flexibilidade na redução de preços ou, ainda, contratação de agentes que podem promover o produto no mercado externo. Podendo também aumentar a sua margem de lucro de $\mathrm{R} \$ 0,57$ para $\mathrm{R} \$ 1,37$ (diferença entre a margem de lucro no mercado interno e no mercado externo) mantendo o mesmo preço que mercado externo tem praticado

Porém é importante frisar que esses valores são estipulados em preços médios, desconsiderando, portanto, quantidades e diferenciação de espécies que tenham maior ou menor valor agregado. 
A Lusamar Pescado compromete cerca de $35 \%$ da receita em custo variável. Isso significa que a margem de contribuição da empresa será de $65 \%$ do preço de venda. Pois a obtenção dessa margem se dá pela dedução dos custos variáveis do preço de venda.

Depois de realizar a dedução de alguns custos variáveis internos que não compõe o custo variável externo (impostos incidente sobre a produção e a venda) e acrescentando os novos custos variáveis (embalagem, transporte e seguro, despachante e despesas aduaneiras) e, principalmente, mantendo os atuais preços de comercialização do produto no mercado, observou-se que a margem de contribuição, representada originalmente por $65 \%$ da receita da empresa passou a para $72,03 \%$. Por essa analise já é suficiente afirmar que a venda externa será uma iniciativa vantajosa para a organização.

A inserção da empresa no mercado internacional, de acordo com os parâmetros anteriormente estudados representa um impacto positivo nas finanças da empresa visto que, não será necessário o investimento em máquinas e adaptação da produção. A Lusamar terá apenas que otimizar a produção de modo que utilize o índice de $20 \%$ de ociosidade de sua capacidade produtiva.

Foi detectado que a margem de contribuição dos produtos exportados é maior que a do mercado interno, gerando um aumento do lucro proporcionando uma alavancagem comercial. $\mathrm{O}$ orçamento de caixa será afetado positivamente pelos impactos acima citados. Terá uma substancial entrada de recursos com um custo financeiro pequeno. Com as entradas de receita a qual proporcionará a capitalização da empresa e com a manutenção dos custos, a ação de escoar o produto para o mercado internacional é de fato viável e representa impactos positivos nas finanças da empresa.

A entrada de recursos na empresa permitira investimento no segmento comercial a fim de alcançar maiores lucros. A empresa que já era capitalizada anteriormente com uma margem de contribuição entorna de $65 \%$ ira demonstrar impactos positivos representada pelas vendas extras que implicam a margem de contribuição de $72,03 \%$

\section{CONSIDERAÇÕES FINAIS}

Com o intuito de analisar o impacto do plano de internacionalização na gestão financeira da empresa a presente investigação buscou observar o segmento de pescado como base norteadora da pesquisa. Considerando o fluxo de caixa médio (conforme tabela 1) da Lusamar Pesca e Comércio de Pescado, empresa não exportadora, e relacionando esses números com os valores de exportações de pescados atuais, verificou-se a viabilidade da iniciativa de adentrar no mercado internacional.

Para tanto foram identificadas diretrizes norteadoras do plano de internacionalização, ou seja, quais procedimentos foram importantes serem abordados para que a empresa obtivesse êxito na tentativa de vender seu produto para o mercado internacional. De posse desses fatores a empresa pode avaliar que áreas deveriam ser privilegiadas para que o produto atendesse as exigências do mercado. A embalagem, notadamente, foi um dos fatores fundamentais para que a empresa pudesse exportar.

A partir de então foi realizado o planejamento financeiro com vistas a justificar a viabilidade de se exportar o pescado comercializado mercado interno. Esse planejamento se deu originalmente pela caracterização financeira da empresa, ou seja, houve, a princípio, o estudo dos parâmetros atuais no mercado interno. 
Dessa forma observou-se que a empresa apresentava uma ociosidade produtiva de $20 \%$ que poderia ser utilizada com a produção destinada ao comercio no exterior. Embora o percentual seja modesto, tendo em vista aos parâmetros elencados pela literatura de manutenção de equilíbrio entre mercado interno e externo, a pesquisa concluiu que, por se tratar por uma atividade experimental, que condiciona a empresa a alguns riscos, seria prudente a manutenção dos custos para que a iniciativa não se tornasse onerosa.

Tendo em vista os valores médios praticados na venda do pescado fresco no mercado externo, e avaliando a margem de contribuição da empresa, no contexto atual e projetando a margem de contribuição do produto com vendas no mercado externo, observou-se que as operações comerciais, em âmbito internacional, podem ser bastante lucrativas.

A empresa, dessa forma poderá se capitalizar utilizando praticamente os mesmos índices produtivos.

Respeitando os fatores limitantes macro-conjunturais e observando as oportunidades do mercado sugere-se que a empresa deva, de fato, comercializar seu produto em âmbito externo. No futuro deverá inclusive destinar cerca de $40 \%$ de sua produção a fim de manter o equilíbrio, conforme sugere Minervini (2001). Dessa forma, as vendas para o exterior capitalizarão a empresa e proporcionarão solidez nas em suas finanças.

Dessa forma, entende-se que o plano de internacionalização é uma alternativa válida para os empreendedores que almejam adentrar no mercado internacional já que reduz significativamente as possibilidades de insucesso no projeto. Nesse sentido esse planejamento realizado em conjunto com o estudo da realidade financeira da empresa, permite a compreensão do contexto organizacional projetado de forma que se analisem os impactos causados por essa mudança. Nessas condições, a empresa pode observar o grau de viabilidade da ação.

\section{REFERÊNCIAS BIBLIOGRÁFICAS}

1. ANDERSON, E. GATIGNON, H. Modes of foreign entry: a transaction cost analysis and propositions. Journal of the international Business Studies, 1996.

2. $\quad$ BARDIN. Laurence. Análise de conteúdo. Lisboa. Edições 70, 2004.

3. BARNEY, J. B. Gaining and studying competitive advantage. Massachusetts: Addison -Wesley, 1996.

4. GITMAN, Lawrence J. e MADURA, Jeff. Princípios de Administração Financeira. $10^{\circ}$. ed. Makron Books: São Paulo, 2005.

5. KIM, Cristian. Estratégias de internacionalização de empresas dos estado do Paraná: o papel dos agentes de exportação. 2007. 158 f. Dissertação (Pos-graduação) Curso de Administração, Departamento de Centro de Pesquisa e Pós-graduação em Administração, Universidade Federal Do Paraná, Curitiba, 2007.

6. LAKATOS, Eva Maria e MARCONI, Marina de Andrade. Metodologia Científica. $3^{\circ}$. ed. São Paulo: Editora Atlas, 2000.

7. MALUF, Sâmia Nagib. Administrando o Comércio Exterior no Brasil. $1^{\text {a }}$ ed., São Paulo: Edições Aduaneiras, 2000.

8. MINERVINI, Nicola. O Exportador. $3^{\circ}$ ed. Makron Books: São Paulo, 2001. 
9. NETO, Alexandre Asaf e SILVA, César Augusto Tibursio. Administração de Capital de Giro. $2^{\circ}$ ed. Atlas. São Paulo, 1997.

10. OLIVEIRA, Djalma de Pinho Rebouças de.Estratégia empresarial - uma abordagem empreendedora. São Paulo: Atlas, 1991

11. PORTAL BNDES. Disponível <www.bndes.gov.br>. Aceesso em 15 de março de 2006.

12. PORTAL MDIC. Disponível <www.desenvolvimento.gov.br/sitio/inicial/index.php>. Aceesso em 15 de março de 2006.

13. PORTAL SEBRE-RN. Disponível em : <www.sebrae.com.br >. Acesso em 14 de março de 2006.

14. Porter, M. E. Estratégia competitiva: técnicas para análise de indústrias e da concorrência, 7. ed. Rio de Janeiro: Campus, 1986.

15. PREVIDELLI. J.J. Estratégias condicionantes da internacionalização de empresas no Mercosul. Enanpad, 1997.

16. ROCHA, A. M .C.; MELO, R. C. The entry Brazilian Services Firms in the Argentian Marketing and the Psychic distance Construct. In: Encontro Anual ANPAD, XXVI, 2002. Anais. Bahia: Salvador. ANPAD, CD ROM, 2002.

17. SAMANEZ, Carlos Patrício. Matemática Financeira aplicações a análise de investimento. $3^{\circ}$ ed Prentice-hall, São Paulo, 2002.

18. VERGARA, S. C. Projetos e Relatórios de Pesquisa em Administração. $1^{\circ}$ ed.Atlas, São Paulo, 1997. 